\title{
THE HAMY SYMMETRIC FUNCTION AND ITS GENERALIZATION
}

\author{
KAIZHONG GUAN
}

Abstract. In the paper we investigate and generalize the Hamy symmetric function: $F_{n}(x, r)=$ $\sum_{1 \leqslant i_{1}<i_{2}<\ldots<i_{r} \leqslant n}\left(\prod_{j=1}^{r} x_{i_{j}}\right)^{\frac{1}{r}}$. The Schur-convexity is discussed and some analytic inequalities are established by use of the theory of majorization.

Mathematics subject classification (2000): 0E05, 26D20.

Key words and phrases: Hamy symmetric function, schur-convexity, theory of majorization.

\section{REFERENCES}

[1] D. S. Mitrinović, Analytic Inequalities, Die Grundlehren der mathematischen Wisenschaften, 1965, Springer, New York, 1970.

[2] P. S. Bullen, Dragoslav S. Mitrinović And M. Vasić, Handbook of Means and Theirs Inequality, Kluwer Academic Publishers, Dordrecht, 2003.

[3] K. Z. GUAN, Schur-convexity of the complete elementary symmetric function, J. of Inequal. and Appl., (in press).

[4] T. Hara, M. UChiYAma AND S. TAKAHASI, A refinement of various mean inequalities, J. of Inequal. and Appl., 2, (1998), 387-395.

[5] H. T. KU, M. C. KU AND X. M. ZHANG, Inequalities for symmetric means, symmetric harmonic means and theirs applications, Bull. Austral. Math. Soc., 56, (1997), 409-420.

[6] A. W. Boberts, Dale E. VArberg, Convex Functions, Pure and Applied Mathematics, 57, Academic Press, New York, 1973.

[7] A. W. Marshall, I. Olkin, Inequalities: Theory of Majorization and Its Application, Mathematics in Science and Engineering, 143, Academic Press, New York, 1979.

[8] H. N. SHI, Refinement and generalization of a class of inequalities for symmetric functions (in Chinese), Math. in Practice and Theory, 4, (1999), 81-84.

[9] G. H. Hardy, J. E. LitTleWOOD AND D. PÓLYA, Some simple inequalities satisfied by convex functions, Messenger Math., 58, (1929), 145-152.

[10] E. F. Beckenbach, R. Bellman, Inequalities, Ergebnisse der Mathematik und ihrer Grenzgebiete, N. F., 30, Springer, Berlin, 1961.

[11] P. S. Bullen, A Dictionary of Inequalities, Pitman Monographs and Surveys in Pure and Applied Mathematics 97, Addison Wesley Longman Limited, 1998.

[12] J. C. KuAng, Applied Inequalities (3nd ed.), Shandong Science and Technology Press, Jinan, 2004.

[13] H. Alzer, On an inequality of Ky Fan, J. Math., Anal. Appl., 137, (1989), 168-173.

[14] H. AlZER, The inequality of Ky Fan and related results, Acta Appl. Math., 38, (1995), 305-354.

[15] N. LeVInson, Generalization of an inequality of Ky Fan, J. Math., Anal. Appl., 8, (1964), $133-134$. 